\title{
Flammability as a biological concept
}

Juli G. Pausas* and Bruno Moreira

CIDE-CSIC, IVIA campus, Ctra. Nàquera Km. 4.5, 46113 Montcada, Valencia, Spain

*Author for correspondence tel: +34 963 424124; email: juli.g.pausas@uv.es

"No description of the variability and predictability of the environment makes sense without reference to the particular range of scales that are relevant to the organism or processes being examined" Levin (1992)

\section{Recurrent fires enhance flammability}

Studies examining plant flammability descriptors as fire-adaptive traits (e.g., Schwilk, 2003; Scarff \& Westoby, 2006; Cowan \& Ackerly, 2010; Saura-Mas et al., 2010; Pausas et al., 2012) are normally formulated within the framework of inclusive fitness theory. In such framework, flammabilityenhancing traits are considered to favour individuals if the elevated flammability confers fitness benefits. In post-fire seeder species (i.e., those with fire-stimulated germination from a persistent seed bank), higher flammability could increase the recruitment opportunities for the offspring of the individual with enhanced flammability by increasing the chance of opening spaces and by producing the necessary cues for triggering germination from the seedbank ('kill thy neighbour' hypothesis; Bond \& Midgley, 1995). This might be specially relevant in non-resprouting (obligate) seeders with strong spatial population structure (e.g., with short-distance dispersal). Because there is some evidence of heritability for both seed dormancy (e.g., Baskin et al., 2000; Huang et al., 2010) and flammability-enhancing traits (e.g. Sampedro et al., 2010), we would expect a selection for higher flammability with repeated fires.

In a recent paper we provided evidence that individuals of an obligate seeder species (Ulex parviflorus, Fabaceae; a shrub from the Mediterranean Basin) growing in populations recurrently burnt (HiFi populations) were more flammable than individuals of the same species in populations arising from old-field colonisation that did not suffer any fire (NoFi populations, i.e., with fireindependent recruitment; Pausas et al., 2012). Specifically, twigs of plants from HiFi populations ignited quickly, burnt slowly and released more heat than twigs of NoFi plants. In addition, HiFi plants had higher bulk density than NoFi plants. Previous studies have showed that bulk density in U. parviflorus (Figure 1), as well as in other shrub species (e.g., Bradstock \& Auld, 1995;

Tachajapong et al., 2008), is associated with higher temperatures and longer residence time of high temperatures in the soil during a fire. Thus, the results at twig and at the whole plant scale were in agreement and suggested that HiFi plants should ignite easily and reach higher temperatures and produce higher heat doses in the soil than NoFi plants (Figure 1). This higher probability of ignition and higher heat in the soil would increase the chance of recruitment of U. parviflorus from the soil seed bank by opening spaces and by enhancing seedling emergence (the heat shock from fire breaks seed dormancy and stimulates germination in this species; Baeza \& Vallejo, 2006; Moreira et al., 2010). Thus, these results are in agreement with the 'kill thy neighbour' hypothesis.

By including our data on $U$. parviflorus bulk density in a fire behaviour model, Fernandes \& Cruz (2012; hereafter F\&C) predict lower fire spread rates in HiFi populations, which implies higher fire residence time and thus higher heat dose in the soil and in the seed bank (Bradstock \& Auld, 1995; Gagnon et al., 2010). Their simple modelling approach inadvertently provides further support to our results, although a modelling framework accounting for variability and uncertainty would have been 
much more appropriate. That is, the conclusions by Pausas et al. (2012) remain firm: in $U$. parviflorus shrublands (a) there is a divergence on flammability traits between populations living in different selective environments, and (b) the mechanism by which plant fitness would be enhanced is driven by the increase in both the probability of ignition and the heat released to the soil.

\section{Diversity of paradigms, metrics and scales}

$\mathrm{F} \& \mathrm{C}$ criticize flammability experiments performed in lab conditions because they are not "adequate surrogates for real-world, full-scale fire behaviour and dynamics", neglecting that predicting realworld broad scale fire behaviour is not necessarily the objective of all flammability studies. Fire has effects at a diverse array of scales and the appropriate metric at which flammability should be measured depends on the scale and on the objective of the study (Levin, 1992). For instance, the duration of soil heating as well as maximum temperatures (Figure 1) are closely tied to biological processes such as post-fire resprouting and seed regeneration (Beadle, 1940; Auld \& O'Connel, 1991; Vesk et al., 2004; Schwilk, 2003; Paula \& Pausas, 2008). However, even though fireline intensity might be a useful metric for modelling fire behaviour, it is often not predictive of soil heating because heat is mainly transferred upwards (Hartford \& Frandsen, 1992; Bradstock \& Auld, 1995). This is why the use of fireline intensity has been discouraged for describing fire effects (Keeley, 2009). On the contrary, the rate of fire spread is related to soil heating, and the relation is negative because faster fires tend to burn both with shorter residence times and higher above the ground than slower-moving fires (Bradstock \& Auld, 1995). In fact, enhancing fire spread rates has been suggested as mechanism for fire protection in plants (Gagnon et al., 2010).

Modelling fire behaviour requires detailed information of the spatial structure of the fuel bed in the landscape at a given time. Unfortunately the simulation by $\mathrm{F} \& \mathrm{C}$ does not consider parameters related to the structure of the ecosystem (e.g., flammability of the coexisting species, the size, cover density and spatial distribution of dead and alive individuals, etc.) and thus their fire spread estimates may be unrealistic at the community and landscape scale. In contrast to fire behaviour modelling, ecological and evolutionary studies of flammability are mainly performed at the individual level and considering long-term processes (fire regimes), because natural selection (and the genetic control) acts on individual trait variation. Indeed, most of these studies perform standardized flammability measurements in leaves or small branches in controlled lab conditions (e.g., size or mass and moisture of the sample is standardized). Although burning full individuals in field conditions could conceptually be a better approach than working at small scale in the lab, the dimensions and logistics of such experiments and the difficulties of making standardized measurements limit the use of this approach. In addition, variability between whole individuals in the field might be due to various causes that are not genetically controlled, rendering them less informative for an evolutionary analysis. An extreme case may be illustrative: the number and cover of dead individuals in a community are important for modelling fire behaviour; however, these values might be of limited relevance for understanding evolutionary processes because they are not genetically controlled (mortality may be distributed among different species and depends on many other factors such as droughts, pests, age, competition, etc.).

Some species enhance their flammability by retaining dead biomass (Keeley \& Zedler, 1998; Schwilk, 2003). For instance, the retention of dead biomass is an omnipresent trait in U. parviflorus (Pausas et al., 2012). While the presence of this trait is probably genetically controlled (e.g., see references on architectural traits in many horticultural plants), the amount of dead biomass retained is unlikely to have a genetic basis as many other local factors (e.g., water availability, microtopography, light incidence) are involved. Consistently, when analysing this trait in U. parviflorus populations with contrasted fire regime, we found high individual variability in standing dead 
biomass and no differences between fire regimes (Pausas et al., 2012).

Flammability is a complex trait that can be defined in different ways (e.g., probability of ignition, heat released, temperature reached, velocity of combustion, fuel structure, chemical composition, etc.) and measured at different scales (from leaves to landscapes). Because all these indicators are not necessary correlated, the simple use of the term flammability can generate some confusion. However, the results became clear when the flammability indicators are viewed in detail and at the scale that is relevant to the organism or process being examined (Levin, 1992).

\section{Research directions}

Fire science is multidisciplinary and needs to recognise the diversity of approaches and the importance of evolutionary biology. We definitively need experimentation in labs, even if they are (necessarily) reductionist, as is most experimental biology. Understanding the evolution of flammability is extraordinary complicated and laboratory experiments can be considered a first step in sorting out this biological phenomenon. As we advance in methods and technology we will perhaps be able to account for the whole phenotypic variability, but currently we are forced to work at smaller scales at risk of being criticized for being reductionist. Experimentation cannot be replaced by computer models in which assumptions are embedded in the code; it is a basic tool in science and useful for the understanding of many biological processes. Lab experiments are also useful for calibrating models that are later used for fire modelling to test alternative management scenarios. Models can be a useful tool for scaling up lab experiments, because these experiments are performed at the scale of selection (individual level) but fire spreads also through communities and landscapes. Fire research and landscape management have historically been based only on the physical paradigm of fire (i.e, fuel management and fire behaviour modelling). This physical framework has yielded remarkable results, yet it has failed to provide an integrative view of how fire shapes nature and how fire-prone ecosystems should be managed for a sustainable world. Only by considering the complementarity of the different disciplines (physics, forestry, ecology, evolution, genetics, etc.) fire science can make a significant advance in land management (Pyne, 2007).

Current trait-based flammability studies might have limitations for predicting broad-scale fire behaviour (but see Schwilk \& Caprio, 2011). However, they contribute to understand the role of fire in generating trait divergence, fire adaptations and, ultimately, species persistence in fire-prone ecosystems (Keeley et al., 2011; Pausas \& Schwilk, 2012). Fire modelling studies also have limitations, but contribute to understand fire behaviour and might be valuable for fire management. Although the flammability concept is useful to foresters and engineers for predicting fire risk and modelling fire behaviour, it is a biological trait and its origin and variability is determined by biological processes. In fact flammability is now becoming a key factor for understanding plant evolution (Keeley \& Rundel, 2005; Bond \& Scott, 2010; He et al., 2011, 2012). With the recent advent of new generation sequencing and genotyping methods, we are closer to the possibility of genotyping whole populations with highly polymorphic makers to infer relatedness among individuals in the field, and thus to fully test the 'kill thy neighbour' hypothesis. In addition, the emerging trait-based discipline of community genetics and the concept of the extended phenotype (Whitham et al., 2003) may provide an appropriate evolutionary framework for linking leaf traits and community flammability. Indeed, community genetics can potentially make a significant contribution to fire ecology (Wymore et al., 2011). Current studies linking traits and flammability at different scales (Schwilk \& Caprio, 2011; Pausas et al., 2012) are contributing to build this promising approach. This is a very exciting time for fire ecology; we hope that fire modelling and landscape management will also benefit from these new emerging ideas. 
Acknowledgements - This work was funded by the VIRRA project (CGL2009-12048/BOS) from the Spanish Government. B.M. is supported by a grant from the Fundação para a Ciência e a Tecnologia (SFRH/BD/41343/2007). We thank V.M. Santana for providing the data for Figure 1, and G..A. Alessio, G. Corcobado, M.C. Castellanos, J.E. Keeley and D. Schwilk for helpful comments on the manuscript.

\section{References}

Auld TD, O'Connell MA. 1991. Predicting patterns of post-fire germination in 35 eastern Australian Fabaceae. Australian Journal of Ecology 16: 53-70.

Baeza MJ, Vallejo VR. 2006. Ecological mechanisms involved in dormancy breakage in Ulex parviflorus seeds. Plant Ecology 183: 191-205.

Baskin JM, Baskin CC, Li X. 2000. Taxonomy, anatomy and evolution of physical dormancy in seeds. Plant Species Biology 15: 139-152.

Beadle N. 1940. Soil temperatures during forest fires and their effect on the survival of vegetation. Journal of Ecology 28: 180-192.

Bond WJ, Midgley JJ. 1995. Kill thy neighbour: an individualistic argument for the evolution of flammability. Oikos 73: 79-85.

Bond WJ, Scott AC. 2010. Fire and the spread of flowering plants in the Cretaceous. New Phytologist 188: 1137-1150.

Bradstock RA, Auld TD. 1995. Soil temperature during experimental bushfire in relation to fire intensity: consequences for legume germination and fire management in south-eastern Australia. Journal of Applied Ecology 32: 76-84.

Cowan P, Ackerly D. 2010. Post-fire regeneration strategies and flammability traits of California chaparral shrubs. International Journal of Wildland Fire 19: 984-989.

Fernandes PM, Cruz MG. 2012. Plant flammability experiments offer limited insight into vegetation-fire dynamics interactions. New Phytologist. (DOI: 10.1111/j.1469-8137.2012.04065.x)

Gagnon PR, Passmore HA, Platt WJ, Myers JA, Paine CET, Harms KE. 2010. Does pyrogenicity protect burning plants? Ecology 91: 3481-3486.

Hartford RA, Frandsen WH. 1992. When it's hot, it's hot... or maybe it's not! (Surface flaming may not portend extensive soil heating). International Journal of Wildland Fire 2: 139-144.

He T, Lamont BB, Downes KS. 2011. Banksia born to burn. New Phytologist 191: 184-196.

He T, Pausas JG, Belcher CM, Schwilk DW, Lamont BB. 2012. Fire-adapted traits of Pinus arose in the fiery Cretaceous. New Phytologist (DOI: 10.1111/j.1469-8137.2012.04079.x)

Huang X, Schmitt J, Dorn L, Griffith C, Effgen S, Takao S, Koornneef M, Donohue K. 2010. The earliest stages of adaptation in an experimental plant population: strong selection on QTLS for seed dormancy. Molecular Ecology 19: 1335.

Keeley JE. 2009. Fire intensity, fire severity and burn severity: a brief review and suggested usage. International Journal of Wildland Fire 18: 116-126.

Keeley JE, Zedler PH 1998. Evolution of life histories in Pinus. In: D. M. Richardson ed. Ecology and biogeography of Pinus. Cambridge (UK): Cambridge University Press, 219-250.

Keeley JE, Rundel PW. 2005. Fire and the Miocene expansion of C4 grasslands. Ecology Letters 8: 683690.

Keeley JE, Pausas JG, Rundel PW, Bond WJ, Bradstock RA. 2011. Fire as an evolutionary pressure shaping plant traits. Trends in Plant Science 16: 406-411.

Moreira B, Tormo J, Estrelles E, Pausas JG. 2010. Disentangling the role of heat and smoke as germination cues in Mediterranean Basin flora. Annals of Botany 105: 627-635.

Levin SA. 1992. The problem of pattern and scale in ecology. Ecology 73: 1943-1967.

Paula S, Pausas JG. 2008. Burning seeds: germinative response to heat treatments in relation to resprouting ability. Journal of Ecology 96: 543-552.

Pausas JG, Alessio GA, Moreira B, Corcobado G. 2012. Fires enhance flammability in Ulex parviflorus. New Phytologist 193: 18-23. 
Pausas JG, Schwilk DW. 2012. Fire and plant evolution. New Phytologist 193: 301-303.

Pyne SJ. 2007. Problems, paradoxes, paradigms: triangulating fire research. International Journal of Wildland Fire 16: 271-276.

Scarff FR, Westoby M. 2006. Leaf litter flammability in some semi-arid Australian woodlands. Functional Ecology 20: 745-752.

Sampedro L, Moreira X, Llusia J, Peñuelas J, Zas R. 2010. Genetics, phosphorus availability, and herbivore-derived induction as sources of phenotypic variation of leaf volatile terpenes in a pine species. Journal of Experimental Botany 61: 4437.

Santana VM, Baeza MJ, Vallejo VR. 2011. Fuel structural traits modulating soil temperatures in different species patches of Mediterranean Basin shrublands. International Journal of Wildland Fire 20: 668677.

Saura-Mas S, Paula S, Pausas JG, Lloret F. 2010. Fuel loading and flammability in the Mediterranean Basin woody species with different post-fire regenerative strategies. International Journal of Wildland Fire 19: 783-794.

Schwilk DW. 2003. Flammability is a niche-construction trait: canopy architecture affects fire intensity. American Naturalist 162: 725-733.

Schwilk DW, Caprio AC. 2011. Scaling from leaf traits to fire behaviour: community composition predicts fire severity in a temperate forest. Journal of Ecology 99: 970-980.

Tachajapong W, Lozano J, Mahalingam S, Zhou X, Weise DR. 2008. An investigation of crown fuel bulk density effects on the dynamics of crown fire initiation in shrublands. Combustion Science and Technology 180: 593-615.

Vesk PA, Warton DI, Westoby M. 2004. Sprouting by semi-arid plants: testing a dichotomy and predictive traits. Oikos 107: 72-89.

Whitham TG, Young WP, Martinsen GD, Gehring CA, Schweitzer JA, Shuster SM, Wimp GM, Fischer DG, Bailey JK, Lindroth RL. 2003. Community and ecosystem genetics: a consequence of the extended phenotype. Ecology 84: 559-573.

Wymore AS, Keeley ATH, Yturralde KM, Schroer ML, Propper CR, Whitham TG. 2011. Genes to ecosystems: exploring the frontiers of ecology with one of the smallest biological units. New Phytologist 191: 19-36.

Key words: flammability traits, fire regime, fire ecology, scale. 


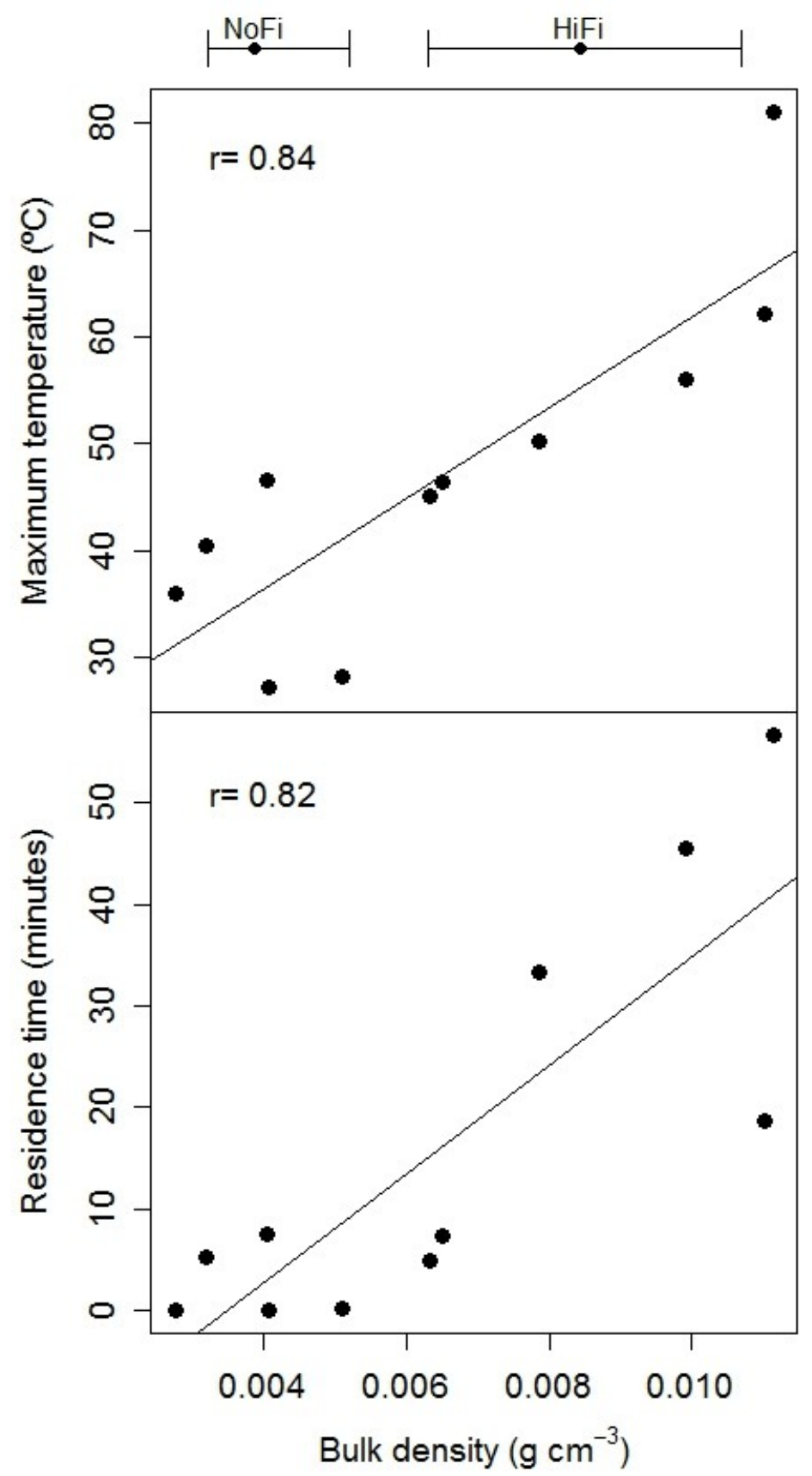

Figure 1. Relation between bulk density (in $\mathrm{g} \mathrm{cm}^{3}$ ) of different individuals of Ulex parviflorus and maximum temperature $\left({ }^{\circ} \mathrm{C}\right)$ and residence time above $40^{\circ} \mathrm{C}$ (in minutes) in the soil profile $(1-\mathrm{cm}$ depth) during experimental fires in the Valencia region, eastern Spain (Santana et al., 2011). Regressions are significant at $\mathrm{p}<0.002$. The segments on the top represent the median and the 25 and 75 percentiles of the bulk density values observed for NoFi and HiFi populations in Pausas et al. (2012). 